\title{
Is Famine Relief Irrelevant to Rural People? ${ }^{1}$
}

\author{
Alex de Waal
}

\section{Introduction}

People who give assistance to the poor tend to sec their assistance as a very important fact in the lives of the poor people who receive that alssistance. even the central fact in the poor people's lives. For the givers of aid, it is a premise that alid is a good thing. Even critics of aid to poor countries, and here we must make a special mention of the critics of food aid, concede that emergency food aid, or famine relicf, is a necessary and good thing. However, I suspect that the support for emergency food aid by these critics is related to the highly emotional nature of most discussions of famine. The subject of famine arouses such strong emotions that rational thought often gives way to superficial moralising. No one wants to be against food aid to famine victims, lest they reap the scorn directed at Malthusian political economists in England in the 1840s:

'I have always felt a certain horror of political economists', said Benjamin Jowett, the celebrated Master of Balliol, since I heard one of them say that the famine of 1848 in Ireland would not kill more than a million people, and that would scarcely be enough to do any good'. [Quoted in WoodhamSmith 1963:375-6].

Nevertheless, while no one is publicly opposed to famine relief in general, there have been many critics of individual relief programmes. Famine relief programmes have been accused of creating dependency. This they are alleged to do by drawing the recipients of relief into client relationships with aid agencies, by depressing grain prices and hence disrupting local food production, by displacing traders from the grain market, or, more insidiously, by producing a state of mind in the recipient population whereby they see themselves as dependent, and lose the motivation towards self-reliance.

This article is based upon a case study of the famine of 1984-85 in Darfur, Sudan, and its immediate aftermath. This case illustrates these points well.

\footnotetext{
Mosl of the empirical conlent of 1 his paper derives from 18 months' work in Sudan. mostly in Darfur. during 1985-87. This was made possible by the supporl of the Economic and Social Research Council of London and Save the Children Fund (UK). Many individuals helped with the research. of whom Malek el Amin deserves a special menlion.
}

During 1985 the aid agencies which gave alssistance to Chadian refugess in Darfur werc concerned that they were attracting local people to their camps. These local people would attempt to parss themselves off als refugees - a relatively simple task as most came from the same ethnic groups als the refugees - and thereby gain alcesss to food rations. The relief angencies were also concerned that food distributed principally in the towns was drawing in the surrounding rural population, creating peri-urban relicf shelters. Later in the famine and during its immediate aftermath. experts working for al rural development programme in the south-west of Darfur became concerned that food aid would have severe negative consequences in the long term:

The farmers in the project area have lost both their markets and their labour supply. This will mean that in future seisons those farmers will be less willing to produce a surplus and the grain required by the deficit areas of north Darfur will have to be supplied continually by grain imported into the region. [Jebel Marra Rural Development Project (JMRDP) 1986:6].

It was feared that the large harvest of 1985, in combination with the continued distribution of free food, would lower the price of grain, make it unnecessary for poor rural people to engage in agricultural wage labour, inflating labour rates and creating a labour shortage, leading to a situation where it would be unprofitable to bring in the harvest, much of which would simply be left to rot in the fields. Hence, during 1984-86 in Darfur, there were people who were arguing for stopping food aid to some sections of the population, because it was having harmful effects, and in some cases, for stopping it altogether.

Many people also argued that food relief was essential. In the first half of 1985, journalists and relief workers predicted that hundreds of thousands, if not millions, would starve in Darfur and the neighbouring regions unless massive amounts of food aid were delivered immediately [de Waal 1987b]. In the following year, 1986, early estimates for Darfur's food aid needs were as high as 75 per cent of those of the preceding year. In January 1986 Oxfam and Save the Children Fund announced to the public that four million Sudanese still faced starvation unless food aid were provided. 
Fortunately, during 1985 millions did not die - in Darfur perhaps 100,000 at most - and during 1986 there were no deaths attributable to the famine. On occasions, relief agencies have claimed some or all of the credit for these "disasters averted'.

The scene is set for a confrontation. Was food aid essential during 1984-86 in Darfur, and did it save much of the population from death and destitution? Or did it, at least in part, have severe adverse consequences leading to the "dependency syndrome"? There is some truth in both claims. However, I think that there is more truth in a third claim, one that is rarely considered in this and similar debates: that famine relief was irrelevant.

\section{Famine Relief and Famine Mortality}

The great majority of famine relief given in Darfur consisted of grain: sorghtum. It was donated in the belief that it would save lives. Between December 1984 and December 1985 nearly 98,000 metric tonnes of grain were distributed, a mean of $32.2 \mathrm{~kg}$ per head. During 1986 a further 61,000 tonnes were distributed. These amounts part of one of the largest peace-time relief operations ever mounted. Yet there is no evidence that consuming this grain saved anyone's life.

In this article l can only summarise data and arguments that I have presented in more detail elsewhere [see de Waal 1989]. Approximately 100,000 people are estimated to have died on account of the famine in Darfur. The majority of these were children aged between one and four years. This ranks the famine as exceptionally severe by modern African standards, though probably not comparable to the famine experienced at the same time in northern Ethiopia. However, the causes of famine mortality were not to be found in reduced consumption of foods.

People in rich and poor families were equally likely to die during the famine. For instance, households which were defined as at or above subsistence level, on the basis of land and animal ownership and off-farm sources of income, had a death rate of 30.1 per thousand per year over the two years from June 1984 to June 1986 (much higher during the peak famine months of January to September 1985). Those defined as below subsistence level had a death rate of 27.5 per thousand per year over the two years. The difference is not statistically significant. The poorest eight per cent of households had a death rate of 34.1 per thousand, not significantly different from the 28.7 per thousand of the remainder.

People in rich and poor villages were equally likely to die. From the ten sites studied, the two poorest had death rates of 30.5 and 25.9 per thousand, and the two richest had death rates of 38.4 and 26.0 per thousand. Those in women-headed households had a death rate of 25.4 , those in male-headed households had a death rate of 29.7. Receipt of food aid made no evident difference to the chances of dying. The figures here are less clear. This is beciuse the sites which received most food aid already had lower mortality rates, despite being poorer, and many places did not receive food aid until the end of 1985, when an excellent harvest was being gathered in, and the situation was already returning to normal.

Excess mortality was instead due to severe localised health crises. The drought and famine caused enormous movements of people, breakdown of sanitation facilities, and an acute shortage of clean water. Under these conditions, potentially lethal diseases such as the diarrhoeas and measles became far more prevalent, and consequently more people died.

Some forms of relief did directly address the causes of excess mortality. Water supplies were improved in a few locations, there were emergency programmes of inoculation against major childhood diseases in other parts. These programmes probably saved lives. The distribution of supplementary foods, such as milk and oils, which can be used for weaning children, probably also had a positive impact on the health of the most vulnerable children. However, sorghum, which represented the majority of the aid, had no such effects.

The proponents of food relief can also argue - and have argued - that it prevented deaths, indirectly. That is, the grain saved lives, not because people consumed it and thereby improved their nutritional status, but because of its impact on people's so-called 'survival strategies'. Specifically, it has been argued that the policy of distributiong food relief to the villages from mid-1985 into 1986 maintained people in those villages. These people would otherwise have migrated to towns and been exposed to lethal health crises. This argument is based on similar premises to the argument that food relief, distributed to the main population centres, is a bad thing in that it draws rural people to these places and thereby precipitates health crises. These lines of argument bring us to a fundamental assumption in the debate for and against food relief: that the presence of food relief significantly influences what rural people, stricken by famine, choose to do. It is the validity of this assumption that needs to be investigated.

\section{Food Relief and the Choice of 'Survival Strategies'}

Did the availability of food relief in certain places draw people to those places, and in the case of people already there, keep them there? At first sight, there appear to be a number of instances which confirm the power of food relief to attract people to it. On closer scrutiny, however, each of these examples appears to 
be slightly suspect. Moreover there are counterexamples which suggest that food relief was a much weaker 'pull factor' than other things could be. These other factors include rainfall during the planting season, and the possibility of earning an income from low-status trades such as selling firewood or water.

One example of the apparent pulling power of food relief is the presence of local people in the Chadian refugee camps in and near Dar Masalit during 1985. The refugee camps themselves were set up on the principle of forcibly moving refugees to them. Those responsible for administering the camps saw such local Sudanese as people enticed by the chance of free food rations, masquerading as refugees to cheat the system. The implication was that these people had abandoned their previous lives, as farmers, for life as a dependent of a relief agency. I have discussed the social and ethnic dynamics of the phenomenon of locals 'becoming refugees' elsewhere, and argued that it was a manifestation of a tradition of ethnic change in response to shifting power relations between communities [de Waal 1988]. In the past, communities that came under the hegemony of a certain ethnic group, say Fur, would obtain security by 'becoming Fur'. In a similar way, during 1985, local people 'became refugees' to enjoy the temporary advantages of that status. However, for the purposes of this argunient, the relevant point is that for local people, moving to a refugee camp did not mean abandoning their farms or turning down alternative sources of income. Most of the Sudanese in refugee camps were extremely local, and while they resided in the camps they also cultivated their fields. By 1986 most of the Chadian residents of the refugee camps were also cultivating in the surrounding villages [Ruiz 1987]. Those who lived further away left the camps at the onset of the rains, precisely in order to cultivate. By living in the camps these people were also not passing up the chance of gaining an income from an off-farm low-status trade; in this area the market in low-status trades collapsed entirely. That is to say, food relief did act as a 'pull factor', but chiefly because of the absence of other competing pull factors.

A second apparent counter-example is the growth of the famine camp at Hujerat, adjacent to Buram town in south Darfur, from no one to 20,000 people between March and May 1985. The immediate cause of the growth of the camp was the policy of the town council, which created the formal entity of the famine camp and made food rations available to all those who registered there. However, most of the people of Hujerat were not 'pulled' immediately from the surrounding rural area. Instead they were villagers who had previously been drawn to the town by the possibility of earning a dry-season income there. By March they were enca mped around Buram in informal squatter camps. Moving to Hujerat did not interfere with their primary reason for migrating to the town, earning an income. When the rains arrived during the planting season, the camp dispersed. Hence the "pull factor' of food relief was only supplementary to a stronger pull factor, that of the chance of earning a dry-season income, and did not counteract the pull factor of cultivating during the wet season.

A third apparent counter-example comes from northeast Darfur. This was the clustering of the populations of small villages around larger population eentres such as Mellit, Saiyah and Malha. These larger centres were receiving most of the aid, which did not begin to reach villages in the northern parts until September and October. However, once again, other pull factors were at work. Specifically, there were opportunities for earning a dry-season off-farm income, which drew people to these centres, and the onset of the rains, which drew them away. A striking example is the people who congregated around Malha, who were some of the most desperate to be found anywhere in Darfur. During June and July, as the rains began, and months before food relief began to reach the villages, these people began to leave Malha and return home to plant. Farmers near Malha town complained of a labour shortage, despite wage rates which had tripled. However, in these cases the critical factor in people's movement was not a pull factor but a "push factor'. Because of the drought, shallow wells in the villages dried up in the dry season of 1984-88, and in the absence of drinking water, people had had no alternative but to move away.

The argument against food relief acting as a significant pull factor is made stronger by investigating instances where it failed to have any effect at all. One such instance is the case of the famine camp at Mawashei, on the outskirts of the regional capital, el Fasher. Most of the people in the camp came during the dry season of 1984-85, from areas close to the town. In this area during this period the pre-head distribution of relief grain was the highest in Darfur. Mawashei itself received no general distribution of food until October 1985. In March and April of 1985 the per-head distribution to the villages near to el Fasher was higher than during the preceding and following months, but the people of Mawashei stayed in the camp, where they received no free food. During May the village distributions fell to a level of one third of that of the preceding months, but most people in Mawashei chose this month to leave the camp. The people said they came to the town in order to earn a dry-season income, and left in order to plant their fields. The timing of their coming and going suggests that this was true, and that the presence of food relief had little impact on what they chose to do.

The comparison of these cases also makes another point. It might be argued that the distribution of relief grain to migrant settlements gave people there more resources, and thereby made it possible for them to 
leave and return to their farms. Howt'er. whilc relief certainly made it easier for people to return. it was not a necessary condition for it. In the places. such as Mawashei. where little or no relief was received. pcople still chose to leave to cultivate at the onset of the rains. and most were able to do so.

In fact. throughout Darfur. during May and June 1985. famine victims left camps where relief was available. towns were casual work was available. and richer rural areas where firm work was available. and went home to villages where none of these were to be had. but where they could begin to cultivate for the coming season. At this time. people were exceptionally hungry: they were tating onct a day or once in two days. and eating mostly grain-substitutes such as wild leaves and berrics. There was no prospect of a harvest for four or five months. Yet people walked awaly from the relief and the chance of an income to buy food. in order to try to grow food for the coming season.

Turning to the immediate aftermath of the famine. there is also littlc evidence for the presence of food relief having a significant impact on the decisions made by rural people. Early pessimism that the 1985 grain harvest would not be brought in. and that richer smallholders would cease to plant large areas of grain. proved to be unfounded. The same project that had earlier forecast these disastrous effects of food aid later reported only 'delays' in harvesting and the utilisation of more family labour [JMRDP 1985. summary p.ii]. It is true that the area planted to grain in 1986 was 17 per cent down on the area in 1985. But this decrease must be seen in the context of the large expansion of area planted to grain in 1985: up to 50 per cent in some parts. When compared to the years 198084 , the area planted to grain in 1986 was merely four per cent less. Moreover. there was an increased planting of groundnuts between 1985 and 1986. amounting to 14 per cent. There was also a shortage of labour during the 1985-86 dry season compared to a year previously. However. much of this shortage was due to incidental factors. such as the escalation of the war in southern Sudan preventing southern migrant labourers from coming to Darfur. and 1984-85 was a year of exceptional over-supply of labour [see de Waal 1987a: 143]. Moreover. much of the work harvesting and threshing is paid in grain. at a fixed rate. Hence. because the post-famine price of grain was much lower than the price during the famine. the real labour rates were also lower [Pearson 1986:2]. Consequently it cannot be argued that labour rates rose during the 1985-86 dry-season. immediately post-famine. and it could be argued that low real rates of pay contributed to the shortage of labour.

Rural people in Darfur showed little sign of any 'dependency syndrome'. In fact their stubborn refusal to take food relief or wage labour when it interfered with the more important tasks of cultivating their own fitld suggests a "self-reliance syndrome". Their own statements about food relicf confirm this: it wis grectcd with surprise. and nobody expected it to continue. In the towns. and among government cmployees. the attitude was very different. These people saw the provision of theap or free food as a right. The government likewise saw an obligation to provide for its own employees and for townspeople. The government's initial plan for food relitf involved distributing substantial amounts - one third of the total - to these groups. When subsidised grain was not available in towns such as el Fasher and Mellit the citizens rioted. However. in rural areas. such perceived governmental duties to citizens did not exist. Here. food relief was instead an unexpected bonus. and nobody made decisions on the expectation that it would continue.

\section{Food Relief and the Success of 'Survival Strategies'}

There is powerful evidence to suggest that the presence of food relief did not substantially alter the decisions that famine victims (and other rural people) made during and immediately after the famine of 1984-85 in Darfur. That is not to say that food relief had no effect. There is also good evidence to suggest that food relief improved people's chances of avoiding destitution during the famine. Evidence for this lies in the comparative trends of sales of small livestock and the taking-out of debts in areas that did and did not receive food relief [de Waal 1987a:134-5]. In mid1985 , in areas that were receiving food relief. people sold fewer animals than before and took out fewer debts than before. Elsewhere. the numbers of sales and new debts were similar to or greater than before. The differences were small but appreciable.

In 1985. relief agencies gave food aid to Darfur with the intent of saving lives. There is no evidence that the food they gave had any direct effect in this respect. The effect of food aid in indirectly preventing deaths is more complex. In some instances. poorly managed food relief probably caused deaths. by creating famine camps such as Hujerat in Buram. Later in 1985. food relief distributed to the villages was one factor among many that kept people from coming to the towns. In both instances it is easy to overstate the importance of food relief in determining what people chose to do. It is not possible to say whether food relief, acting indirectly. caused fewer deaths than it prevented: only that the numbers involved were relatively small.

For those who advocated food relief to Darfur in 1984-85. the fact that it served to prevent a certain amount of destitution was an incidental benefit. For those who received the aid. the prevention of destitution was of primary importance. Famine victims in Darfur held that they had no control over 
their chances of dying during the famine. They did believe that they had power over their chances of preventing destitution, that is, preserving the basis of their future livelihood. Consequently, their primary aim during the famine was not to minimise that probability of dying. but to keep their animals alive, and to cultivate. The strategies they followed are therefore better described as 'anti-destitution strategies' than "survival strategies". Rural people used food relief as one resource in order to assist them to preserve their assets and cultivate. Frequently they stored it for consumption later on, such as during the planting season. Even when the distribution had been minimal, people who left relief camps frequently took with them a sack or more of grain, saved from their rations. On other occasions they sold relief grain to buy more important items, such as seeds, tools or transport home. In this respect food relief was not irrelevant. instead it was a rather inefficient form of incomesupplement.

During 1986, the rationale of food relief to Darfur changed. It was distributed with the explicit aim to preventing further impoverishment among the vulnerable population, so that rural people could reestablish their livelihoods: the programme was designed primarily as a transfer of income, not as a means of nutritional support. ${ }^{2}$

\section{Conclusion}

This article has come to strong conclusions about the role - or lack of it - of famine relief with respect to rural people's survival during the famine of 1984-85 in Darfur. These conclusions should not be uncritically generalised. For example, the situation in northern Ethiopia is different in two important respects: wild foods are much less available; and the area has a much longer and more continuous tradition of statecraft, and much more recent experience of food aid. Darfur has not been subject to close government cont rol since the early years of the century, and 1984-85 was the first large food aid programme ever in the region. The state, and consequently organised relief, is much more ideologically distant in Darfur than many other parts of the world.

It is easy to overstate both the positive and negative effects of food relief. Perhaps this is because food relief is much more important in the lives of relief agency employees, local government administrators, and

2 A discussion of the rationale of this programme, the measurement of vulnerability, and the effects of the distribution are beyond the scope of this paper. For details of this programme: see Buckley 1988. consultant academics than it is in the lives of rural people. Certainly, it is among the officials of district councils and regional ministries in Sudan that the 'dependency syndrome' is to be found, and not among the farmers and pastoralists. The presence of relief agencies and food aid often seemed to divert the attention of such officials from long-term developmental issues, and to remove from them the responsibility for tack ling local problems. Food aid as famine relief was relevant to rural people in Darfur, but it was relevant in unexpected ways. It was much less relevant in preventing destitution than were other factors in the conomy and ecology of the region, and it was largely irrclevant to physical survival.

The implication of this is that rather than arguing for and against food relief, as though it were the only possible form of large-scale famine relief, one should recognise its severe limitations, and investigate other forms of relief, that might directly save lives and prevent destitution. In the present debate on famine relief, or rather, the present lack of debate, food relief does have one fundamental negative impact. By its existence it obscures the need for effective forms of famine relief.

\section{References}

Buckley, R., 1988, 'Food targetting in Darfur: Save the Children Fund's Programme in 1986, Disasters vol 12 no 2

de Waal A.. 1987a, Famine that Kills: Darfur 1984-5. Report to Save the Children Fund, London

$-1987 \mathrm{~b}$, 'The perception of poverty and famines', International Journal of Moral and Social Studies vol 2 no 3

-1988 . 'Refugees and the creation of famine: the case of Dar Masalit, Sudan', Joumal of Refugee Studies vol 1 no 2

-1989. 'Famine mortality: a case study of Darfur, Sudan 1984-5", Population Studies vol 43 no 1

Jebel Marra Rural Development Project, 1985. Preliminary Grain Production Estimates for the Project Area, JMRDP, Zalingei

-1986. Annual Report 1985-6: Annex II. Monitoring and Evaluation Department, JMRDP, Zalingei

Pearson, M. 1986, Household Returns to Grain Production. JMRDP, Zalingei

Ruiz. H., 1987, When Refugees won't go Home: The Dilemma of Chadians in Sudan, US Committee for Refugees, Washington DC

Woodham-Smith, C., 1963, The Greal Hunger: Ireland 1845-49. Harper and Row, New York 